\title{
Cytotoxic, acute toxicity and phytotoxic activity of Callicarpa macrophylla in various models
}

\author{
Barkatullah $^{1}$, Muhammad Ibrar ${ }^{1}$, Muhammad Nafees', Abdur Rauf ${ }^{2,}$, , Haroon Khan ${ }^{3}$ \\ ${ }^{1}$ Department of Botany, University of Peshawar, Peshawar-25120, Pakistan \\ ${ }^{2}$ Institute of Chemical Sciences, University of Peshawar, Peshawar-25120, KPK, Pakistan \\ ${ }^{3}$ Department of Pharmacy, Abdul Wali Khan University Mardan-23200, Pakistan
}

Email address:

mashaljcs@yahoo.com (A. Rauf), mashalics@gmail.com (A. Rauf)

\section{To cite this article:}

Barkatullah, Muhammad Ibrar, Muhammad Nafees, Abdur Rauf, Haroon Khan. Cytotoxic, Acute Toxicity and Phytotoxic Activity of Callicarpa macrophylla in Various Models. American Journal of Biomedical and Life Sciences. Special Issue: Phytochemical and Pharmacological Study of Medicinal Plants. Vol. 3, No. 2-1, 2015, pp. 1-4. doi: 10.11648/j.ajbls.s.2015030201.11

\begin{abstract}
The present study describes the cytotoxic, acute toxicity and phytotoxic activities of Callicarpa macrophylla belonging to family Verbanaceae. Brine shrimps cytotoxic bioassay of crude extract of bark of C. macrophylla (CBE) showed 975.22 $\mathrm{LD}_{50}$ value and crude extract of leaves of $C$. macrophylla (CLE) showed no significant results. However, all the test

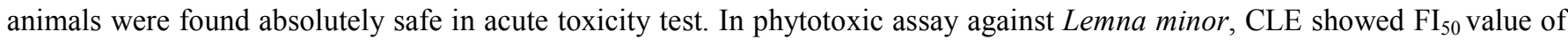
464.55 and CBE showed no significant results. In conclusion, the CLE showed significant phytotoxic activity and therefore, could be a useful natural herbicidal.
\end{abstract}

Keywords: Callicarpa macrophylla, Cytotoxicity, Acute Toxicity, Phytotoxicity

\section{Introduction}

Callicarpa macrophylla Vahl. commonly known as Sumli in Punjabi. The fruits are a striking feature of the genus; hence the genus name "Callicarpa", meaning "handsome fruit", and the common name "beautyberry". It is an erect shrub globally distributed across India, Nepal, Bhutan, Myanmar, South East Asia, and China [1]. In Pakistan this plant is distributed in tropical and Sub-Himalayan regions. It is also reported that this plant is cultivated in Peshawar and Lahore [2].

The folklore claims that the plant is used for the treatment of different diseases and disorders such as diarrhea, dysentery, headache and stop bleeding [1]. It can also be used to treat burns [3] and for intestinal worms, skin disorders and to "purify the blood" [4]. Extracts of this plant also show antiinflammatory, antifungal and antibacterial activities [5]. Several glycosides, saponins, steroids, tannins, flavonoids, fatty acids, fixed oils etc. are known to be constituents of this plant [1]. From the above description it is clear that Callicarpa macrophylla is an important medicinal plant locally use for various ailments. Therefor in the present study, this plant is explored preliminarily for their pharmacological potential.

\section{Materials and Methods}

\subsection{Preparation of Extract}

The fresh leaves and bark of Callicarpa macrophylla were collected in January 2013, from Botany Department, University of Peshawar and University of Agriculture Peshawar. The leaves and bark were separated from branches. The collected leaves and bark were shade dried and size reduced by laboratory grinder into powder. $50 \mathrm{~g}$ of each sample was soaked in $250 \mathrm{ml}$ methanol and acetone for $72 \mathrm{~h}$. Thereafter plant extract was passed through Whatman filter paper No. 1823. This process was repeated or 3 times. Evaporating in a rotatory evaporator at $40{ }^{\circ} \mathrm{C}$ was carried out to concentrate the extracts. These extracts were stored at $4{ }^{\circ} \mathrm{C}$ priors to use. The methanolic and acetone extracts and the standard drug were dissolved in dimethylsulphoxide (DMSO) at the concentration of 10 and $1 \mathrm{mg} / \mathrm{ml}$ for cytotoxic and 30 and $1 \mathrm{mg} / \mathrm{ml}$ for phytotoxic activities, respectively.

\subsection{Experimental Animals}

$\mathrm{BALB} / \mathrm{c}$ mice of either sex were used in all experiments. Animals were purchased from the Pharmacology Section of 
the Department of Pharmacy, University of Peshawar, Peshawar, Pakistan. The animals were maintained in standard laboratory conditions $\left(25{ }^{\circ} \mathrm{C}\right.$ and light/dark cycles i.e. $\left.12 / 12 \mathrm{~h}\right)$ and were fed with standard food and water ad libitum. The experimental protocols were approved by the ethical committee of the Pharmacy Department, University of Peshawar, Peshawar, Pakistan.

\subsection{Cytotoxic Activity}

Brine shrimp lethality bioassay [6] technique was applied for the determination of general toxic property. Here, lethality test has been carried out using brine shrimp nauplii eggs (Artemia salina). Eggs were placed in one side of a small tank divided by a net containing $3.8 \% \mathrm{NaCl}$ solution for hatching. In the other side of the tank was placed a light source to attract the nauplii. After 2 days of hatching period the nauplii were ready for the experiment. Four mg of the extract was accurately measured and dissolved in DMSO to get varying concentrations of 10,100 and $1000 \mu \mathrm{g} / \mathrm{ml} .3$ vials were taken for each concentration. Ten brine shrimp nauplii were then placed in each vial. For the control test of each vial, one vial containing the same volume of DMSO plus water up to $5 \mathrm{ml}$ was used. After $24 \mathrm{~h}$ of incubation, the vials were observed using a magnifying glass and the number of survivors in each vial were counted and noted. From these data, the percentage of mortality of the nauplii was calculated for each concentration and the half maximum lethal concentration $\left(\mathrm{LC}_{50}\right)$ values were determined [7].

\subsection{Acute Toxicity Test}

The acute toxicity study was carried out for the crude ethanolic extract of leaves (CLE) and bark (CBE) of the selected plant. The study was carried out using albino mice weighing $20-25 \mathrm{~g}$ of either sex. The animals were randomly distributed into six groups each of six animals. The animals were acclimatized to the laboratory conditions before the commencement of experiment. All the animals were deprived from food overnight, the control group received normal saline and the remaining II-IV groups were treated with 500, 1000 and $2000 \mathrm{mg} / \mathrm{kg}$ body weight respectively with crude ethanolic extract of leaves, while group V-VII groups were treated with 500, 1000 and $2000 \mathrm{mg} / \mathrm{kg}$ respectively with ethanolic extract of fruit. The animals were observed continuously for the first $4 \mathrm{~h}$ and then for the next $24 \mathrm{~h}[8,9]$.

\subsection{Phytotoxic Activity}

The phytotoxic activity of Callicarpa macrophylsla were evaluated using Lamna minor as test species following recommended procedure [10,11]. Different concentrations of extract $10,100,1000 \mu \mathrm{g} / \mathrm{ml}$ were made there flasks were taken for each concentration. $20 \mathrm{ml}$ of E. medium was added to each flask. Other flasks (3 for each) were supplemented with E. medium and standard drug (Atrazine) served as negative and positive control. To each flask ten plants with 23 fronds were transferred and kept all the flasks under about $12 \mathrm{~h}$ day light conditions. Plants were observed daily and on the seventh day the numbers of fronds were counted. The \% growth inhibition was recorded with reference to the negative control using the following formula; [8].

$$
\text { Inhibition } \%=\frac{(100-\text { Number of fronds in test sample })}{(\text { Number of fronds in negative control })} \times 100
$$

\subsection{Statistical Analysis}

The resulting data is expressed as mean of three different experimental findings. For statistical analysis, GraphPad 6 version was used.

\section{Results}

\subsection{Effect of Cytotoxic Activity}

The crude methanolic extract of leaves and bark of $C$. macrophylla were evaluated using brine shrimps lethality bioassay. The CBE showed significant cytotoxicity at 1000 $\mu 1$ dose while the $\mathrm{LD}_{50}$ was calculated as $975.22 \mu \mathrm{l} / \mathrm{ml}$. However, CBE did not show any significant cytotoxic effect at all doses (Table 1).

\subsection{Effect of Acute Toxicity Test}

The results of crude methanolic extract of leaves and bark of C. macrophylla are displayed in table 2. All the test animals were found safe up to the maximum test dose (2000 $\mathrm{mg} / \mathrm{kg}$ ) for both extract of leaves and bark. Similarly, no gross behaviour changes were observed during $24 \mathrm{~h}$ assessment.

\subsection{Effect of Phytotoxic Assay}

The screening of the crude methanolic extract of both leaves and bark of $C$. macrophylla were carried out using Lemna minor as test species (Table 3). CLE showed significant phytoinhibition. A significant inhibition was observed at $1000 \mu \mathrm{l}$ dose of leaf which showed $464.55 \mathrm{FI}_{50}$ value and $\mathrm{CBE}$ was non-significant at all test doses.

\section{Discussion}

The present study describes the preliminary safety profile of the crude methanolic extract of both leaves and bark of $C$. macrophylla in both in-vitro and in-vivo studies with significant phytotoxicity against L. minor.

Brine shrimp cytotoxic assay a simple, economical and efficient method of screening of test articles for anti-cancer potential [8]. Primarily, components having cytotoxic activity are considered as anticancer agents. When the crude extract of barks and laves of the plant was tested in brine shrimp cytotoxic assay, no such anticancer potential was observed and thus ruled out the presence of anticancer constituents in the extracts of both leaves and barks of the plant. Additionally, the extracts of both leaves and barks the plant neither impart any change in animal behavior in acute toxicity test nor caused any mortality and thus was found absolutely safe during $24 \mathrm{~h}$ assessment times. 
Interference of weeds noticeably diminishes the quality and quantity of agricultural crops and is responsible for huge economic losses all over the world. It is estimated in US alone that weeds cause a loss of at least $12 \%$ costing to nearly US\$ 33 billion while the situation is more alarming in developing countries [7]. Pakistan is an agriculture country yielding high quality and quantity of various crops and cereals. Due to poor weed control strategies, large quantity of these crops may be damaged. Synthetic herbicides are extensively used for the control of weeds in agricultural sectors. However, various factors that restricted the use of synthetic herbicides include water and soil pollution, herbicide-resistant weed populations, herbicide residues and detrimental effects on nontarget. The degree of harm caused by the uncontrolled weeds is usually more than that of insects and diseases but its effects are unseen. They also reduce the crops yield due to competition for sunlight, water and fertilizer. In addition, weeds provide habitat for insects which help in spreading the disease. So weeds controlling is very essential for the increasing the production of various crops [8].

In our current findings, the crude methanolic extract of both leaves and bark of C. macrophylla showed considerable phytotoxicity in a concentration dependent manner.

\section{Conclusion}

In short, the crude methanolic extract of both leaves and bark of C. macrophylla exhibited absolute safety in both invitro and in-vivo models with significant phytotoxicity in concentration dependent manner. However, the isolation of pure molecules from the extracts will be useful in characterizing the chemical background of phytotoxic activity.

Table 1. Cytotoxic activity of leaf and bark of C. macrophylla.

\begin{tabular}{|c|c|c|c|c|c|}
\hline Parts & Conc. $(\mu \mathrm{l})$ & Total no. of shrimps & No. of shrimps survived & \%age inhibition & $\mathbf{L D}_{50}$ \\
\hline \multirow{3}{*}{ CLE } & 10 & 10 & 8 & 20 & \multirow{3}{*}{1182.16} \\
\hline & 100 & 10 & 7 & 30 & \\
\hline & 1000 & 10 & 5 & 50 & \\
\hline \multirow{3}{*}{ CBE } & 10 & 10 & 7 & 30 & \multirow{3}{*}{975.22} \\
\hline & 100 & 10 & 6 & 40 & \\
\hline & 1000 & 10 & 5 & 50 & \\
\hline
\end{tabular}

Table 2. Acute toxicity of leaf and bark of C. macrophylla.

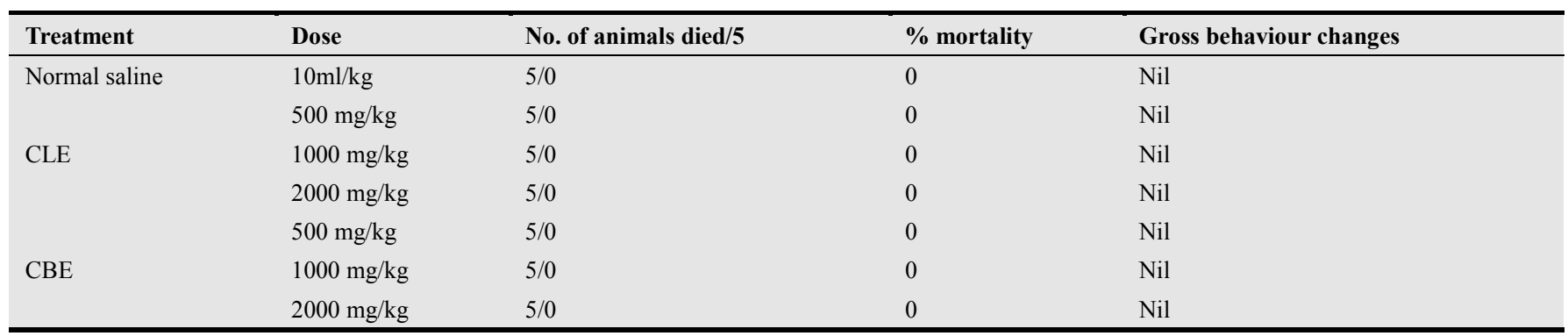

Table 3. Phytotoxic activity of leaf and bark of C. macrophylla.

\begin{tabular}{|c|c|c|c|c|c|}
\hline Parts & Conc. $(\mu \mathrm{l})$ & No. of fronds in test & No. of fronds in ethanol (-ve control) & \%age inhibition & $\mathbf{F l}_{50}$ \\
\hline \multirow{3}{*}{ CLE } & 10 & 30 & & 37.5 & \\
\hline & 100 & 26 & 48 & 45.83 & 464.55 \\
\hline & 1000 & 23 & & 52.08 & \\
\hline \multirow{3}{*}{ CBE } & 10 & 35 & & 27.08 & \\
\hline & 100 & 30 & 48 & 37.5 & 8196.80 \\
\hline & 1000 & 28 & & 41.66 & \\
\hline
\end{tabular}

\section{References}

[1] V. Yadav, S. Jayalakshmi, R. K. Singla, and A. Patra, "Preliminary assessment of Anti-Inflammatory activity of Callicarpa macrophylla Vahl. leaves extracts," Indo-Global J. Pharma. Sci. 1(3), 219- 222, 2011.

[2] A. A. Munir, "A taxonomic revision of the genus Callicarpa 1. (verbenaceae) in Australia," J. Adelaide Bot. Gard. 6(1), 5-39, 1982.
[3] D. Bensky, A. Gamble, and T. Kaptchuk, Chinese Herbal Medicine: Material Medica. Seattle: Eastland Press; 1986.

[4] Khare CP, editor. Indian Herbal Remedies: Rational Western Therapy, Ayurvedic and Other Traditional Usage, Botany. New York: Springer-Verlag; 2004.

[5] R. K. Verma, A. K. Singh, P. Srivastava, K. Shanker, A. Kalra and M. M. Gupta, "Determination of Novel Plant Growth Promoting Diterpenes in Callicarpa macrophylla by HPLC and HPTLC," J. Liq. Chromato. Related Technol. 32(16), 2437-2450, 2009. 
[6] H. Khan, M. A. Khan, and Abdullah, "Antibacterial, antioxidant and cytotoxic studies of total saponin, alkaloid and sterols contents of decoction of Joshanda: Identification of components identification through thin layer chromatography," Toxic. Indus. Health, 2012. DOI: 10.1177/0748233712468023.

[7] S. M. Shah, S. Hussain, A. Khan, H. Khan, F. Ullah, and B. Tullah, "Cytotoxic and phytotoxic actions of Heliotropium strigosum," Toxic. Indus. Health, 2013. DOI: 10.1177/0748233712471706.

[8] Barkatullah, M. Ibrar, and N. Muhammad, "Evaluation of Zanthoxylum armatum DC for in-vitro and in-vivo pharmacological screening," Afr. J. Pharm. Pharmacol. 5(14): 1718-1723, 2011
[9] A. Rauf, G. Uddin, B. S. Siddiqui, A. Khan, H. Khan, M. Arfan, and A. Wadood, "In-vivo antinociceptive, antiinflammatory and antipyretic activity of pistagremic acid isolated from Pistacia integerrima," Phytomedicine, 21(12), 1509-1515, 2014.

[10] I. Khan, H. Ahmad, N. Ali, B. Ahmad, and H. Tanoli, "Screening of Bunium bulbocastanum for antibacterial, antifungal, phytotoxic and haemagglutination activities," Pak. J. Pharm. Sci., 26(4), 787-791, 2013.

[11] G. Uddin, A. Rauf, B. S. Siddiqui, and H. Khan, "Cytotoxic Activity of Extracts/Fractions of Various Parts of Pistacia Integerrima Stewart," Transl. Med. 3(118), 2161-1025 2013. 